\title{
Optimization of Starch Biopolymer Enriched with Chitosan Containing Rosemary Essential Oil and its Application in Packaging of Peanuts
}

\author{
Zainab Sayyahi ${ }^{1}$, Faranak Beigmohammadi ${ }^{* 2}$, Shahram Shoaiee ${ }^{1}$
}

1-Department of Food Science and Technology, Faculty of Agriculture, Ashtian Branch, Islamic Azad University, Iran.

2-Department of Food Science and Technology, Faculty of Agriculture, Kermanshah Branch, Islamic Azad University, Kermanshah, Iran.

\section{A B S T R A C T}

Background and Objectives: Studies on packaged food by activated biopolymer starch films containing antimicrobial material is interesting field of food. Science This study investigates the effect of chitosan and rosemary essential oil on properties of starch films and peanut were packaged in them.

Materials and Methods: In this study, composite films based on starch containing 0, 2, 4, 6 and $8 \%$ chitosan and values of $0,0.5,1,1.5$ and $2 \%$ rosemary essential oil produced by casting method, peanut packaging in them and the growth of Aspergillus flavus and aflatoxin $\mathrm{B}_{1}$ production were investigated up to 12 days; as well as, the optimal point and regression model with RSM, Minitab 17.

Results: Results of films showed chitosan and rosemary had decreasing effect on water vapor permeability, solubility and moisture absorption and increasing effect on tensile strength. The optimal point for physical properties of film was proposed $2 \%$ rosemary and $7.27 \%$ chitosan. In addition, the film reduced number of Aspergillus flavus about $4700 \mathrm{cfu} / \mathrm{g}$, both chitosan and rosemary had a significant effect in this respect, although rosemary effect was more. The decreasing effect in the production of aflatoxin was found. The microbial optimal condition for film with $2 \%$ rosemary and $4 \%$ chitosan was created after 12 days, which showed the antimicrobial effect of film over time.

Conclusions: It seems, rosemary has a major variable to improve physical and microbial properties of the films, while, chitosan has significant effect on physical properties.

Keywords: Rosemary essential oil, Aspergillus flavus, Aflatoxin, Peanut, Starch-chitosan biopolymer

\section{Introduction}

Packaging industry with applying innovative materials and packaging methods has played an important role in reducing food wastes as well as produce healthier products (1). Eco-friendly packaging based edible films which mostly are made from polysaccharides, proteins, fats, or a combination of them are of special importance day-to-day due to natural materials, renewable ability as well as prevention from environmental pollution (2). On the other hand, the potential of such films as the carriers of antimicrobial and antioxidants agents and other active agents to improve quality, increase shelf life, control pathogens and improve the organoleptic properties of the food have provided many applications for them in food packaging industry (3).

Starch polysaccharide is the main source of plants. It involves as granules in different sizes and shapes. The most important sources of it include grains (including corn, wheat and rice), potatoes, and cassava (4). Chitosan (a natural carbohydrate polymer) obtained by the deacetylation of chitin from shells of crab shrimp and crawfish (5). Recently, the combination of chitosan with starch in the form of composite films is with the aim of covering physical defect such as sensitivity to chitosan moisture and fragility of starch film $(6,7)$. Rosemary is a plant of 
Lamiaceae family has a permanent woody stem and green and fragrant leaves. This plant is traditionally used as an additive and flavoring in food (8). Among the component forming rosemary essential oil, the maximum value related to 1,8 cineol $(33.08 \%)$, camphor (18.13\%), $\alpha$-pinen $(9.23 \%)$, $\alpha$-Terpineol (8.17\%), borneol (5.48\%), camphene (5.07\%) and pcymene $(2.42 \%)$. Hydrophobic properties is one of the properties of rosemary essential oil and its constituents leading its accumulation in the cell membrane, disrupt its structure and increasing the permeability of cell membrane (9). Bonilla et al. (10) examined the properties of wheat starch film and the effect of chitosan on these films. Addition chitosan caused significant increase in the surface charge of particles and apparent viscosity of the film and the production of shiny and thicker films. Also, water vapor permeability by adding chitosan increases. In wheat starch-chitosan films, when the chitosan was $50 \%$, the antimicrobial effect observed is high. Teodoro et al. (11) in their study examined the properties of rosemary essential oil and its antimicrobial effect in fresh dough. The highest growth inhibitory effect on the Aspergillus was in a concentration of 10 micrograms per liter.

So far, studies on packing peanuts by activated biopolymer starch film with antimicrobial material reinforced with chitosan and investigating the effect of rosemary essential oil in inhibiting the growth of Aspergillus flavus has not been done, so this research is unprecedented in its kind.

\section{Materials and Methods}

Peanut was acquired from the market and until the tests were stored at $4^{\circ} \mathrm{C}$. Potato starch (relative humidity 18-21\%), chitosan (with average molecular weight and deacetylation degree of 75-85\%) both from the Sigma-Aldrich USA, glycerol as a plasticizer, dextrose agar, potato dextrose agar mediums from Merck Germany, Aspergillus flavus PTCC5004 from fungi collection center of Iran Industrial Research Organization and rosemary essential oil were prepared from Young Living, USA.

Various amounts of chitosan including 0, 2, 4, 6 and $8 \%$ in $1 \%$ acetic acid $(\mathrm{v} / \mathrm{v})$ is solved for $10 \mathrm{~min}$ at $40^{\circ} \mathrm{C}$ on a magnetic mixer. Then, the solution to separate the possible unresolved particles was passed from the cheesecloth. To prepare starch soluble, $4 \mathrm{~g}$ starch added to $100 \mathrm{ml}$ distilled water and kept at $90^{\circ} \mathrm{C}$ for 10 minutes until gelatinization, it was cooled to a temperature of $50^{\circ} \mathrm{C}$. Next, after addition of glycerol to starch (30\% of starch weight), chitosan and starch solutions mixed on a magnetic mixer and eventually rosemary essential oil with $0,0.5,1,1.5$ and $2 \%$ added to the solution and stirred with homogenizer for 2 minutes at 120,000 rpm. Finally, film-forming solution was spreading on edged Plexiglas containers $(20 \times 20$ dimensions constructed by Borna Novin Plast (Iranian Company) and drying at $50^{\circ} \mathrm{C}$ for 20 hours. After drying, film was separated from the containers clearly and continuously. It should be noted that all $\%$ are by weight and considered compared to the starch dry matter (12).

To measure the thickness of samples, the Japan Mitutoyo digital micrometer with measuring precision of $0.001 \mathrm{~mm}$ was used. Each film thickness was measured at five points, and then the average thickness was determined and used in water vapor permeability calculations and tensile strength test (13).

Measuring tensile strength (TS) was done in the method of D882 -ASTM (14) by tensile testing machine SANTAM, STM-600 model made in Iran. Before tension tests, all samples for 1 hour were placed in the relative humidity of $50 \%$ at $25^{\circ} \mathrm{C}$ which created by calcium nitrate. Films were cut in the form of $2.5 \times 10 \mathrm{~cm}^{2}$ rectangles. The distance between the two device jaws were set $10 \mathrm{~cm}$ with a speed of 50 $\mathrm{mm}$ per minute, and the load cell $50 \mathrm{~N}$ is used.

In measuring water vapor permeability, E96-95 ASTM (15) method was used. First, films were qualified in relative humidity of 50\%. The special vials with $4.5 \mathrm{~cm}$ height for measuring water vapor permeability were used. There was a hole in the lid of these vials with a diameter of $11 \mathrm{~mm}$ which a piece of tested film was placed in this part using an ear cleaner and liquid oil in the way that oil was not placed on the film surface and prevents from vapor permeability. 3 $\mathrm{g}$ calcium sulfate which provides a relative humidity of $0 \%$, were placed inside the vial. Vials and their contents were weighed and placed inside desiccator containing a saturated solution of potassium sulfate. Saturated potassium sulfate at $25^{\circ} \mathrm{C}$ makes $97 \%$ relative humidity. Desiccator was placed inside incubator within $25 \pm 1{ }^{\circ} \mathrm{C}$ and weighed for 6 days every several hours at 0.001 scales. Then the curve of vials weight gain was plotted using Excel 2010 over time and after calculating linear regression, slope of the line obtained was calculated. By dividing the line slope of each vial to the level of whole film exposed to water vapor transmission, water vapor transmission 
rate (WVTR) was achieved. Then, permeability to water vapor (WVP) using the following equation was calculated:

$$
\text { Water vapor permeability }=\frac{\mathrm{WVTR}}{\mathrm{P}(\mathrm{R} 1-\mathrm{R} 2)} \times \mathrm{X}
$$

$\mathrm{X}$ : Film thickness based on the meter ; P: vapor pressure of pure water at $25^{\circ} \mathrm{C}$ according to Pascal with an average of 3169 Pascal

$R_{1}$ : relative humidity inside the desiccator $(97 \%) R_{2}$ : relative humidity inside the vial $(0 \%)$ the amount of $P\left(R_{1}-R_{2}\right)$ is 3073.93 psi.

To measure moisture absorption rate, Angles and Dufresne methods (16) were used. Film samples with dimensions of $20 \times 20 \mathrm{~mm}$ were cut and placed inside the desiccator containing calcium sulfate with relative humidity of $0 \%$ for 24 hours. After primary weighing, the samples transferred to the desiccator containing a saturated solution of calcium nitrate at $55 \%$ relative humidity in $20-25^{\circ} \mathrm{C}$. Then, the weight of samples in every 24 hours by scale with an accuracy of 0.0001 is measured until reaching constant weight which occurred during 72 hours, the moisture absorption rate was calculated from the following equation:

Moisture absorption $(\%)=\frac{W_{t}-W_{0}}{W_{0}} \times 100$

$\mathrm{W}_{\mathrm{t}}$ : Sample weight after time $\mathrm{t}$ at a relative humidity of $55 \%$, $\mathrm{W}_{0}$ : Sample initial weight

To determine the solubility in water, film samples were placed inside desiccator containing calcium sulfate for 24 hours. Then, $500 \mathrm{mg}$ of samples were immersed in $50 \mathrm{ml}$ of distilled water stirred temporarily and for 24 hours at $23^{\circ} \mathrm{C}$ placed inside incubator. After that, the films were removed from the water and moved back into desiccator containing calcium sulfate has achieved constant weight. During 96 hours, films reached a constant weight and with weighing the samples again, final dry weight was obtained (17). The $\%$ of water-soluble substance in $\%$ was calculated using the following formula:

Solubility in water $=\frac{W_{1}-W_{2}}{W_{1}} \times 100$

$\mathrm{W}_{1}$ : initial dry weight $\quad \mathrm{W}_{2}$ : final dry weight

To investigate the effect of rosemary essential oil on the fungi growth, A. flavus PTCC 5006 lyophilized culture was used. To activate the lyophilized culture, according to the manufacturer's instructions, ampoule containing fungi was broken in a sterile condition and transferred by $1 \%$ normal saline solution in the form of suspension on prepared medium of potato dextrose agar. Incubation was done at $28^{\circ} \mathrm{C}$ for a week. Then, A. flavus was separated from initial medium and cultured in sabouraud dextrose agar linearly and incubated at $28^{\circ} \mathrm{C}$ for a week. The Neubauer slide was used for counting fungal spores and after, counting the number of $10^{6}$ spores per $\mathrm{ml}$ were chosen for study.

In order to sterilize the peanut, sterilization was done by immersion peanuts in a 3\% solution of sodium hypochlorite and then washed with distilled water and placed on filter paper inside sterile plates. Then, spore suspension $\left(10^{6}\right.$ spores per $\left.\mathrm{ml}\right)$ were placed on peanuts and inoculated peanuts with $A$. flavus packaged in 100 grams packages in the starchchitosan composite film containing rosemary essential oil by heat sealing machine of Preplast, Iran and, microbial tests were done on the peanuts during regular time interval. Microbial test expressed in the ISIRI, 997 (18) have been used in order to rosemary essential oil impact on A. flavus in peanuts examined. Then, the desired dilutions were cultured in the sabouraud dextrose agar medium and incubation performed at $28^{\circ} \mathrm{C}$. In the next stage of cultivation and during growing and reproducing period (57days), resulting colonies that was objective, counted with colony counter in the medium.

In order to evaluate the effect of rosemary essential oil on the amount of produced aflatoxin in peanuts, chromatography test with high performance (HPLC), Waters model equipped with a fluorescence detector, USA was used (19). Aflatoxin extracted from samples using methanol and water (ratio of 8:2) and its fat separated with hexane; then obtained extract using a certain volume of diluted water and extract was passed from immunoaffinity columns containing specific antibodies of aflatoxins Group B and G. With passing diluted extract through the column, toxin in the antigen extract was attached to the antibodies present in the column. Toxin attached to the antibody is washed in the column by passing methanol through the column and collected in the vial, diluted with water. The amount was determined using reverse phase method of liquid chromatography with high-performance which equipped with postcolumn derivatization. The amount with comparing the area under the curve or standard curves height with the unknown sample was calculated taking the dilution factor.

Statistical Analyses: Response surface methodology and central composite design were chosen for modeling. In this study, three independent variables including, the $\%$ of chitosan $\left(\mathrm{X}_{1}\right)$ and the \% of rosemary essential oil $\left(\mathrm{X}_{2}\right)$ at five levels for film properties, while indexes were changed for microbial assay including time $\left(\mathrm{X}_{1}\right)$, chitosan $\left(\mathrm{X}_{2}\right)$ and rosemary 
$\left(\mathrm{X}_{3}\right)$. This design has a block and 5 repetitions at the central point (to calculate the repeatability of the process). Minitab 17 software to analyze data and charts related to the response surface methodology and to find the process optimal conditions was used. The general form of the multivariate model is a general regression model:

$$
Y=\beta_{0}+\sum_{i=1}^{2} \beta_{i} X_{i}+\sum_{i=1}^{2} \beta_{i j} X_{i}^{2}+\sum_{i} \sum_{j=i+1} \beta_{i j} X_{i} X_{j}
$$

In this equation, $\mathrm{Y}$ is anticipated answer for each variable, constant coefficient $\beta 0$, coefficients of linear effects $\beta 1$ (constant coefficient of chitosan), $\beta 2$ (constant coefficient of rosemary), and coefficients of quadratic effects $\beta 11, \quad \beta 22$ and coefficient of interaction $\beta 12$.

\section{Results}

Physical properties of films: According to Table 1, it seems medium and high percent of chitosan and medium and low percent of rosemary could improve the physical properties of films.

The thickness of produced films is measured at 5 points and their average is reported $1.2 \mathrm{~mm}$.

Table 2 shows analysis variance related to the film properties and microbial properties of peanut. Data are assessed at confidence interval of $95 \%$; so that, $\mathrm{p}<0.05$ represents a significant factor in response. As can be seen, chitosan and rosemary had significant effect on tensile strength and quadratic effects can be seen in equations while, interaction between rosemary-chitosan has no significant effect. These results also confirmed using a proposed regression model in Equation 1. In equations related to film properties $\mathrm{X}_{1}$ is chitosan and $\mathrm{X}_{2}$ is rosemary. Rosemary coefficient and rosemary square coefficient are more than chitosan represents its more effect on tensile strength. By comparing F-value of these factors can be concluded that the rosemary essential oil had a greater effect on tensile strength. In addition, no significant lack of fit is also a good measure to the suitability of the model. Regression model confirms the above results suggest that chitosan and rosemary with positive coefficients increase tensile strength.

Eq.1:

Tensile strength $=1.052+0.127 \mathrm{X}_{1}+0.333 \mathrm{X}_{2}+0.0330 \mathrm{X}_{1}^{2}+0.603 \mathrm{X}_{2}^{2}$

Figure 1.a shows the simultaneous effect of both rosemary and chitosan on the value of tensile strength.

As specified in Table 2, for water vapor permeability, $\mathrm{p}$-value in the model is less than 0.05 , which represents the significance of the model at a confidence level of $95 \%$. Among the studied indexes of direct or linear effects, indexes of chitosan and rosemary have been significant and could have a significant effect on water vapor permeability. Among other indexes, only square root of chitosan effect is significant. The coefficients of chitosan and rosemary are the same; according to F-values can be said that the effect of chitosan is much more than rosemary essential oil value. Also, the indirect effects of both are more effective than the square root effect (refer to F-value, too). The regression model in Equation 2 also confirmed the above results suggest that chitosan and rosemary with negative coefficients reduce water vapor permeability.

Eq.2:

Water Vapor Permeability $=+0.001-0.00 \mathrm{X}_{1}-0.00 \mathrm{X}_{2}-0.00 \mathrm{X}_{1}^{2}$

Table1. Physical test results of chitosan-starch composite films

\begin{tabular}{|c|c|c|c|c|c|c|}
\hline \multirow[b]{2}{*}{ Treatment } & \multicolumn{2}{|c|}{ Independent variables } & \multicolumn{4}{|c|}{ Dependent variables } \\
\hline & $\begin{array}{c}\text { Chitosan \% } \\
\left(\mathrm{X}_{1}\right)\end{array}$ & $\begin{array}{c}\text { REO(Rosemary Essential Oil ' } \% \\
\left(\mathrm{X}_{2}\right)\end{array}$ & $\begin{array}{c}\mathrm{TS} \\
(\mathrm{MPa})\end{array}$ & $\begin{array}{l}\text { WVP }\left(\times 10^{-7} \mathrm{~g} /\right. \\
\text { m.h.pa })\end{array}$ & $\begin{array}{c}\text { Moisture Absorption } \\
(\%)\end{array}$ & $\begin{array}{l}\text { Solubility } \\
(\%)\end{array}$ \\
\hline 1 & 6 & 1.5 & 2.00 & 2 & 21.12 & 89.40 \\
\hline 2 & 4 & 1.0 & 1.10 & 2 & 27.12 & 88.45 \\
\hline 3 & 0 & 1.0 & 1.15 & 3 & 39.72 & 99.54 \\
\hline 4 & 2 & 1.5 & 2.00 & 3 & 34.10 & 96.32 \\
\hline 5 & 4 & 0.0 & 1.10 & 2 & 29.46 & 84.88 \\
\hline 6 & 4 & 1.0 & 1.00 & 2 & 28.18 & 86.50 \\
\hline 7 & 4 & 1.0 & 1.10 & 2 & 28.94 & 88.45 \\
\hline 8 & 4 & 1.0 & 1.10 & 2 & 26.98 & 88.45 \\
\hline 9 & 2 & 0.5 & 0.95 & 3 & 36.65 & 93.65 \\
\hline 10 & 4 & 1.0 & 1.00 & 2 & 27.84 & 88.45 \\
\hline 11 & 8 & 1.0 & 2.00 & 1 & 19.84 & 88.81 \\
\hline 12 & 6 & 0.5 & 1.14 & 2 & 21.92 & 89.19 \\
\hline 13 & 4 & 2.0 & 2.20 & 2 & 24.80 & 86.64 \\
\hline
\end{tabular}


Table 2. Variance Analysis of physical properties of films and microbial properties of peanut.

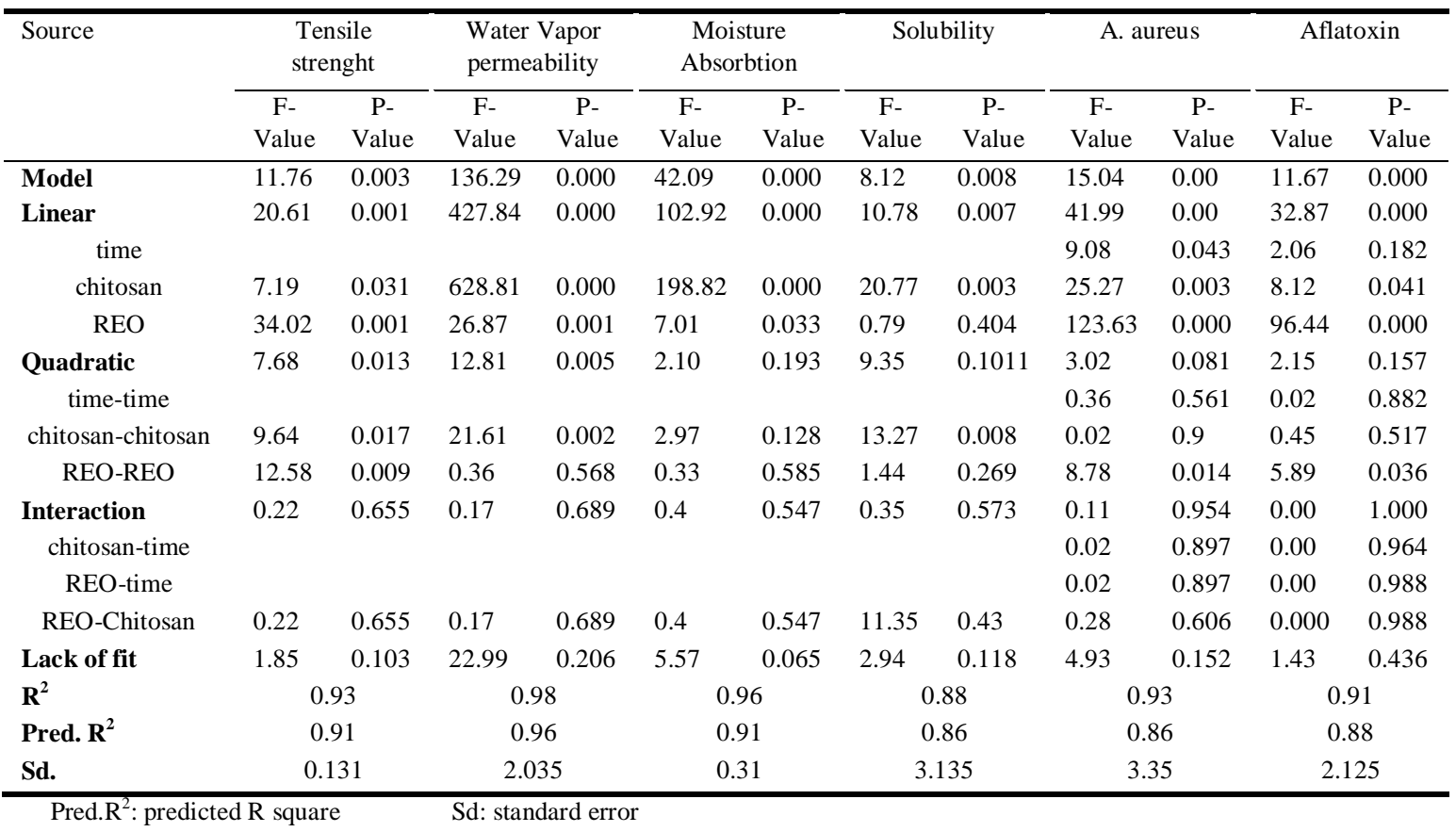

Figure 1.b shows response surface diagram of chitosan and rosemary essential oil simultaneous effects on water vapor permeability.

Variance analysis results relating moisture absorption (Table 2) represents, both independent variables of chitosan and rosemary essential oil has a significant effect on the moisture absorption of starchchitosan composite film and the F-values of these factors suggest that chitosan has been more effective than rosemary essential oil. According to the regression model in equation 3 , chitosan and rosemary essential oil are both negative and chitosan coefficient has been more than rosemary essential oil, which represents its more effectiveness in reducing moisture absorption.

Eq.3:

Moisture absorption $=+44.33-4.244 \mathrm{X}_{1}-2.54 \mathrm{X}_{2}$

Figure 1.c shows the changes process of moisture absorption with $\%$ changes of chitosan and rosemary essential oil.

Based on variance analysis results of solubility are shown in Table 2, chitosan had significant effect. The regression model of equation 4 confirms this issue and shows that chitosan and chitosan- rosemary essential oil interaction due to negative coefficients reduce the solubility of starch-chitosan film; while, chitosan square has a positive coefficient and positive effect on the solubility of starch-chitosan film. It seems that rosemary essential oil alone is not effective on the solubility of starch-chitosan film; while, its interaction effect with chitosan reduces the solubility which may be due to hydrophobic structure of chitosan and essential oil because they will intensify each other.

Eq.7 Solubility $=+95.12-3.92 \mathrm{X}_{1}+0.396 \mathrm{X}_{1}^{2}-$ $0.61 \mathrm{X}_{1} \times \mathrm{X}_{2}$

Figure 1.d shows response surface diagram of simultaneous effect of chitosan and rosemary on solubility index. As the variance analysis and regression model of equation 4 mentioned, increasing the chitosan concentration causes a substantial drop in the solubility. Finally, $7.27 \%$ chitosan concentration and $2 \%$ rosemary essential oil are determined as optimum conditions for physical properties of films. Also, the desirability of this optimization is 0.98 which is an appropriate amount.

Microbial properties of peanut: After microbial test on peanuts packaging in starch-chitosan composite films and according to Table 3, it is observed that the treated film No.8 containing 4\% chitosan and $2 \%$ rosemary essential oil with $1900 \mathrm{cfu} / \mathrm{g}$ A. flavus and $0.67 \mu \mathrm{g} / \mathrm{kg}$ aflatoxin $B_{1}$ have the lowest number of mold and toxin production (during 6 days) and the treated film No.5 with $4 \%$ chitosan and $0 \%$ rosemary essential oil with $6600 \mathrm{cfu} / \mathrm{g}$ A. flavus and $2.49 \mu \mathrm{g} / \mathrm{kg}$ aflatoxin $B_{1}$ have the highest number of mold and toxin production, respectively. 

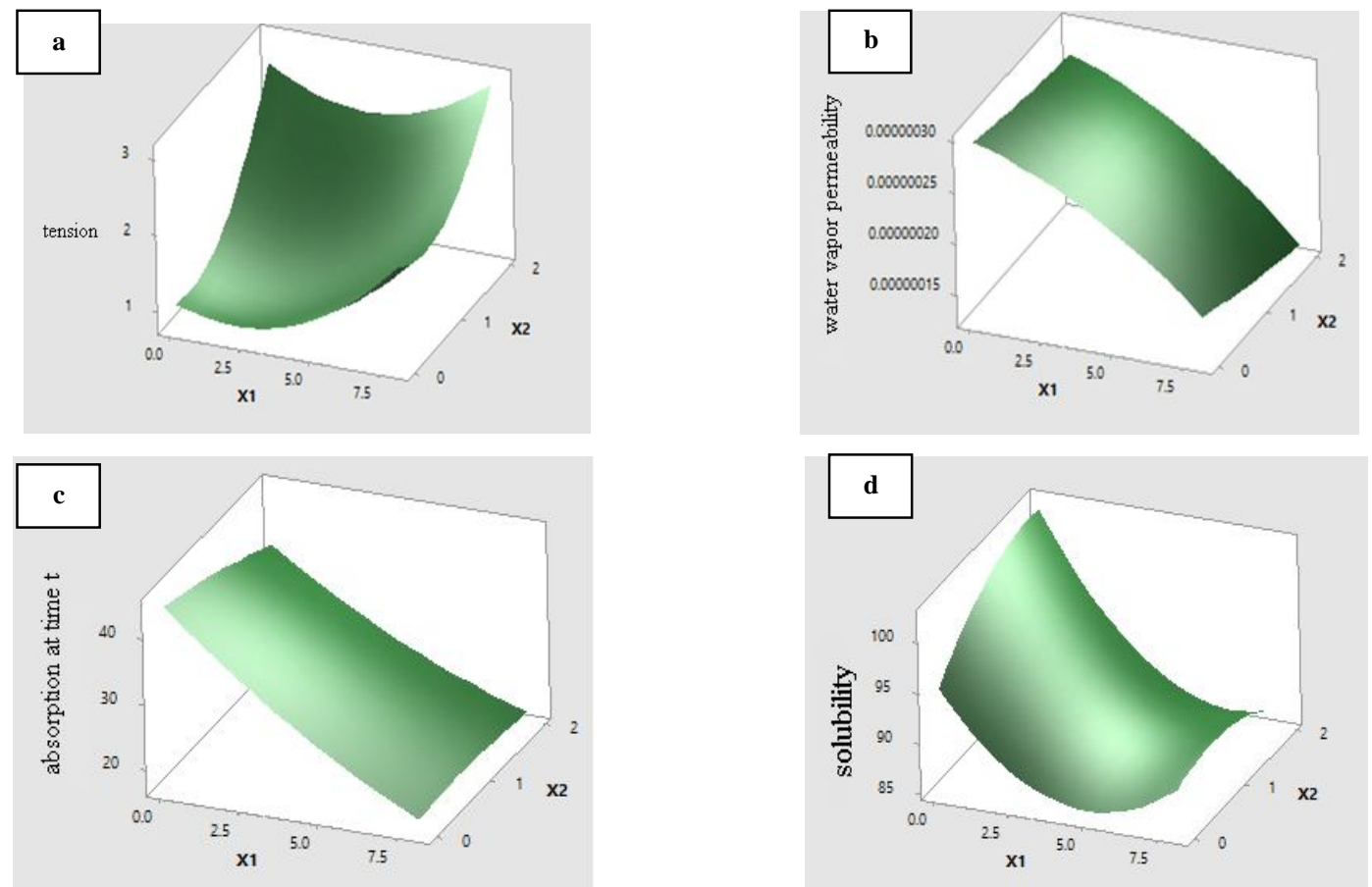

Figure 1. Three-dimensional diagram of simultaneous effect of chitosan $\%\left(\mathrm{X}_{1}\right)$ and Rosemary essential oil \% $\left(\mathrm{X}_{2}\right)$ on a: tensile strength, b: water vapor permeability, c: moisture absorption, d: solubility

Results variance analysis of $A$. flavus number in peanuts Table 2 shows, the factors of time $\left(\mathrm{X}_{1}\right)$, chitosan $\left(\mathrm{X}_{2}\right)$, rosemary $\left(\mathrm{X}_{3}\right)$ and rosemary square have significant effect on A. flavus growth. F-value indicates that the effect of rosemary is more than time and chitosan. This result is also confirmed by predicted regression model in Equation 8. In this model, only rosemary coefficient is negative cause reducing the number of mold.

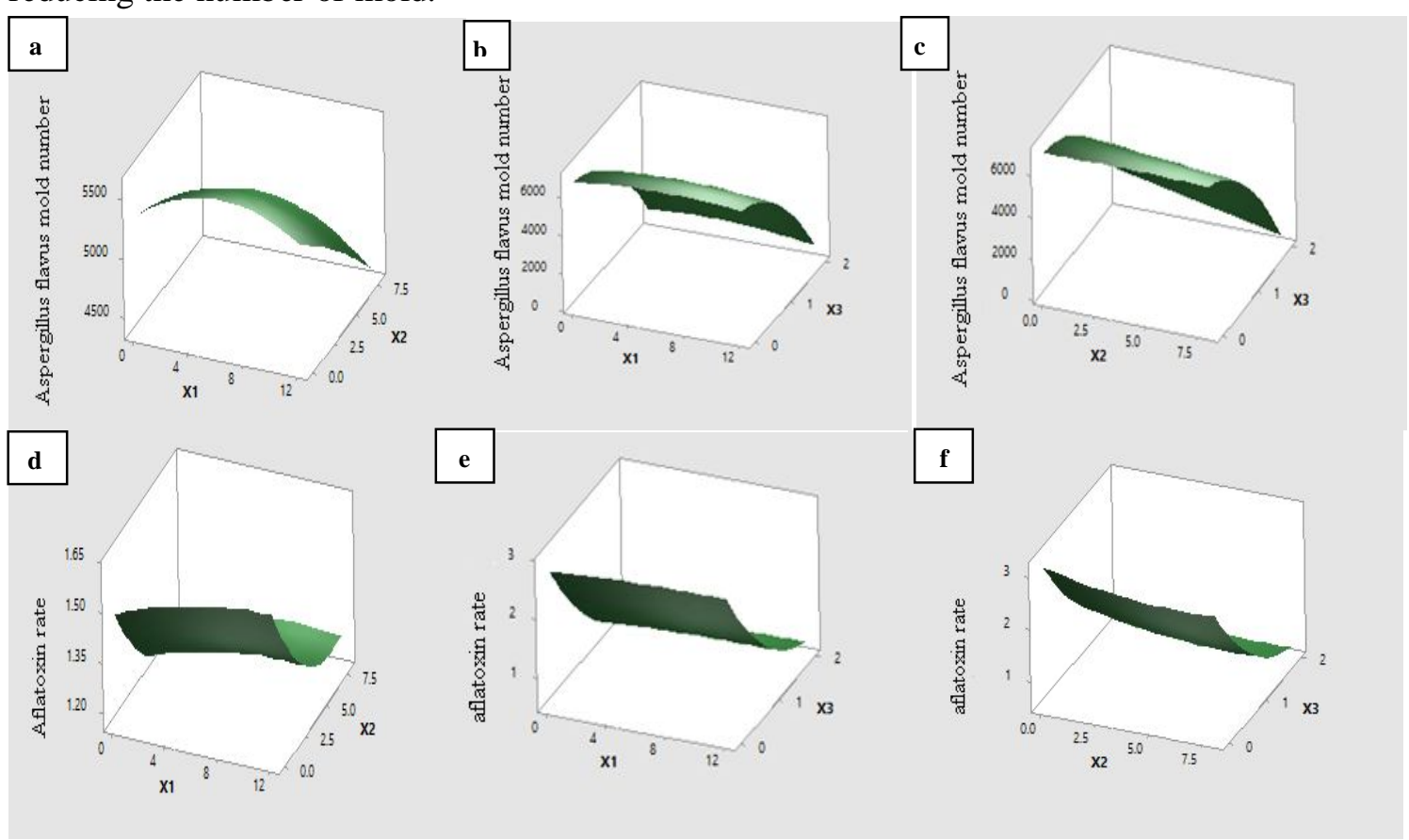

Figure 2. $a, b$ and c Three-dimensional diagram of simultaneous effect of time $\left(\mathrm{X}_{1}\right)$, chitosan $\%\left(\mathrm{X}_{2}\right)$, rosemary $\%\left(\mathrm{X}_{3}\right)$ on A. flavus mold number, and $\mathrm{d}$, e and $\mathrm{f}$ on aflatoxin rate.
Eq. 5:

A.flavus $(\mathrm{cfu} / \mathrm{g})=+6534+106 \mathrm{X}_{1}+68 \mathrm{X}_{2}-63 \mathrm{X}_{3}-1255 \mathrm{X}_{3}^{2}$

Figure 2.a shows the simultaneous effect of time and chitosan value on the changes of A. flavus colonies. In the current form, chitosan shows more slope and also more effect, which is mentioned in the variance analysis table and regression model. 
Increasing the amount of chitosan reduces the number of molds and this reduction is almost linear with steep slope; while, the effect of time has been far less and not makes a huge difference in the number of mold.

In response surface diagram of figure 2.b, the simultaneous effect of rosemary essential oil and time on mold number changes have been shown. The effect of rosemary essential oil is far more than the effect of time and increasing the amount of rosemary cause intense reduction in mold number which is emphasized in variance analysis table and regression model. Also as noted, there is no important change of mold growth through storage time.

Figure 2.c shows the simultaneous effect of rosemary essential oil and chitosan on the number of mold. Again in current form, the great effect of rosemary essential oil on mold number changes is emphasized. Also, increasing chitosan causes a slight reduction (less slope) in the number of mold; however, the rosemary effect is not considerable which variance analysis table and regression model is emphasized.

Variance analysis results in the production of aflatoxin $B_{1}$ are shown in Table 2. Time, rosemary and rosemary square have significant effect on the amount of aflatoxin production that among these factors, the effect of rosemary essential oil has been decreasing; although, time positive coefficient is very small, however, statistical data know it effectively. This result is in line with rosemary essential oil effect on reducing the growth of A. flavus as well. Another point is the lack of time significant effect on aflatoxin production. The proposed regression model in equation 6 has confirmed the reduction effect on toxin production and also shows other statistical factors.

Eq. 6:

Aflatoxin $\mathrm{B}_{1}(\mu \mathrm{g} / \mathrm{kg})=+3.049+0.0190 \mathrm{X}_{1}-2.006 \mathrm{X}_{3}-0.442 \mathrm{X}_{3}^{2}$

Figure 2.d shows respond surface diagram of chitosan and time on aflatoxin rate. In this diagram it is clear that the effect of chitosan is more than time and produced toxin rate has been reduced with increasing it. This reduction is relatively and appropriate steep slope and shown in variance analysis table and regression model. According to this diagram, the lowest toxin production is related to the early maintenance days and maximum $\%$ of chitosan; while, the highest toxin production is related to the final maintenance days and minimum $\%$ of chitosan. Response surface diagram of figure 2.e examines the effect of rosemary and time on toxin production. In this diagram, the limited effect of time is specified and in contrast, rosemary with increasing in a steep slope has been able to decrease the amount of toxin produced. This issue considering outlined cases in the variance analysis table and regression model is predictable well.

Figure 2.f shows the response surface diagram of toxin changes with rosemary and chitosan concentration changes which represents rosemary advantage to chitosan in controlling toxin production. As it is specified, increasing rosemary with much steeper slope compared to chitosan cause a drop in the toxin production; while increasing the amount of chitosan is not so obvious and has not caused certain loss to compared to rosemary.

Table 3. Microbial test results of $A$. flavus and aflatoxin for peanuts in the composite films.

$\left.\begin{array}{ccccc}\hline \text { Treatment } & \text { Time }(\mathrm{X} 1)(\text { day) } & \begin{array}{c}\text { Chitosan }\left(\mathrm{X}_{2}\right) \\ (\%)\end{array} & \begin{array}{c}\text { ROE }\left(\mathrm{X}_{3}\right) \\ (\%)\end{array} & \begin{array}{c}\text { Aspergillus flavus } \\ (\mathrm{cfu} / \mathrm{g})\end{array} \\ \hline 1 & 6 & 4 & 1 & 5400 \\ (\mu \mathrm{g} / \mathrm{kg})\end{array}\right)$


In microbial tests, optimum conditions to minimize mold growth and minimum toxin production are defined. Considering the optimal conditions of the storage time process (12 days), it is observed that the treated film containing $4 \%$ chitosan and $2 \%$ rosemary essential oil with $2350 \mathrm{cfu} / \mathrm{g}$ A. flavus and $0.78 \mu \mathrm{g} / \mathrm{kg}$ aflatoxin $\mathrm{B}_{1}$ have the lowest number of mold. Also, the desirability degree of this optimization is 0.92 which is an appropriate value.

\section{Disc ussion}

Improving the mechanical properties of starch film by adding chitosan is a result of intermolecular hydrogen bonds between starches $\mathrm{OH}^{-}$with chitosan $\mathrm{NH}^{+}$functional group $\left(\mathrm{NH}_{2}\right)$ of chitosan combines with protein in the acidic environment forms $\mathrm{NH}^{+}$, while the crystalline structure of starch by the gelatinization cluttered and groups of $\mathrm{OH}^{-}$are ready to combine with $\mathrm{NH}_{3}{ }^{+}$associated with increasing the strength of the film (12). Chillo et al. (20) produced starch films containing different $\%$ of chitosan using response surface methodology and concluded that chitosan in the amount of $0.55 \%$ increases film mechanical properties such as tensile strength which is consistent with the results obtained from our films. In addition, Zhai et al. (7), Silva-Weiss et al. (21), Shen et al. (22), Bourtoom and Chinnan (6) and Bongyekan et al. (23) also concluded that tensile strength of starch-chitosan film increases with increasing the amount of chitosan. According conducted research, addition antimicrobial compounds to various polymers due to the molecular level changes cause changing the mechanical properties of these films produced from these polymers (3). The results obtained in this study corresponded with this investigation.

Abdollahi et al. (13) reported that the water vapor permeability decreased with increasing concentrations of rosemary essential oil in chitosan film. It is likely that the hydrophobic property of rosemary essential oil reduced its water vapor permeability. Bongyekan et al. (23) reported that the water vapor permeability of starch film reduces with adding chitosan, which this reduction effect in starch film may be due to chitosan hydrophobic property regarding the presence of chitosan hydrophobic acetyl groups. Shen et al. (22) and Vasconez et al. (24), Talja et al. (25), Chillo et al. (20), Xu et al. (12) in their study concluded that the water vapor permeability of starch film with adding chitosan reduced due to interactions and hydrogen bonding between starch and chitosan leading reduce the availability of hydrophilic groups and water vapor permeability. The results obtained in this study corresponded with this investigation.

Bongyekan et al. (23) and Zhai et al. (7) concluded that starch films covered with chitosan had less water absorption than starch film due to the hydrophobicity of chitosan. Also, Pranoto et al. (26) stated; reducing moisture can be due to disposal effect of non-polar compounds in the essential oils on the water molecule.

Bourtoom and Chinnan (6) in their study stated that the solubility of starch film by adding chitosan is reduced. The development of these properties has been attributed to establishing hydrogen bonding between chitosan and starch. Also Shen et al. (22) in their investigation had examined physical properties of potato starch film in combination with chitosan different concentrations $(0,5,10$ and $15 \%)$. When $15 \%$ chitosan was added to the starch film, the solubility reduced from $13.93 \%$ to $4.54 \%$ which is due to strong hydrogen bonding between chitosan and starch as well as chitosan hydrophobicity. Vasconez et al. (24) also stated that in the starch-chitosan film, there is a reverse correlation between the chitosan content and solubility of films due to chitosan hydrophobicity that can be responsible for fewer interactions between water and film matrix. The results obtained in these studies correspond to this study.

Abdollahi et al. (13) concluded that rosemary essential oil used in the chitosan film had antimicrobial property against Listeria monocytogenes and Streptococcus agalactiae, whereas the chitosan film alone was lacking this property. Also Rasooli et al. (27) concluded that rosemary essential oil in $5 \mathrm{ml}$ concentration causes inhibition of A. flavus growth. These researchers attributed the antimicrobial property of rosemary essential oil to diterpene phenol compounds such as carnosic acid, carnosol, rosmanol, Isorosmanol and rosmanic acid, while Yan et al. (28) concluded that rosemary essential oil used in the starch-alginate film was not effective on A. niger, but had great antiEsherichia coli effect. The differences in sensitivity may be caused by different cell structure or function.

Hydrophobic property is an important feature of rosemary essential oil and its constituents which enable them in accumulation in the cell membrane 
disrupt in the membrane structure and increasing cell membrane permeability of microorganisms (9). Teodoro et al. (11) in their study reported that $A$. flavus is sensitive to rosemary essential oil. Rosemary at a concentration of 10 micrograms per liter has the highest growth inhibitory effect on A. flavus and its complete growth inhibition occurs in the concentration of 20 micrograms per liter. Sikkma et al. (29) attributed the antimicrobial activity of essential oils to having phenolic and aromatic compounds. These compounds penetrate the cell membrane and could also affect the clotting of cell contents. Also, studies conducted by Debases et al. (30) suggest that the essential oil of basil, coriander, cumin and rosemary with concentration of 1000 micrograms per liter inhibit the growth of A. flavus. Moghtader et al. (31) in their study stated that rosemary essential oil with concentrations of 0.5 and 0.25 micrograms per liter had strong antifungal activity on A. flavus compared gentamicin. Also, they stated that a large \%age of the antifungal activity of rosemary essential oil is attributed to monoterpenes $\alpha$ pinene. These investigations correspond with the results of our research.

Studies conducted by Deabes et al. (30) suggested that the essential oil of basil, coriander, cumin and rosemary in concentrations of 500, 700, 1000 micrograms per liter have prevented from aflatoxin B1 production. Rasooli et al. (27) concluded that rosemary essential oil at a concentration of 450 micrograms per liter prevent from aflatoxin biosynthesis. Antifungal property and aflatoxin production inhibitory have been attributed to the constituents of rosemary essential oil. It is reported that one of the terpenes groups in the rosemary essential oil (borneol, camphor, 1, 8 cineole, $\alpha$ pinene, verbenone and bornyl acetate) is responsible for antifungal properties of essential oils $(32,33)$. One of the characteristic of deactivation processes is limitation of aflatoxin production as a result of spore formation and mycelium proliferation inhibition (34).

\section{Conclusion}

Chitosan-starch composite films containing rosemary essential oil produced in this research easily separated from the mold sheets, which indicated the appropriate moisture of the film. Chitosan and rosemary both increased the tensile strength of the film. Both of these factors also reduced the water vapor permeability, moisture absorption and solubility of the film; which interaction effect of chitosanrosemary was significant leading reduce solubility. In other above dependent variables, interaction effect of two factors could be seen. Rosemary essential oil reduced A. flavus growth and aflatoxin $\mathrm{B}_{1}$ production; while chitosan in this case was lacking antimicrobial property. The microbial optimal conditions in film with $2 \%$ rosemary essential oil and $\underline{4} \%$ chitosan was created after 12 days maintenance indicated the antimicrobial effect of film over time. Also, the optimum conditions of physical tests for film with concentration of $7.27 \%$ chitosan and $2 \%$ rosemary essential oil was created. It seems, rosemary has a major variable to improve physical and microbial properties of the films, while, chitosan has significant effect on physical properties.

\section{Acknowledgement}

Authors would like to express their sincere gratitude to Islamic Azad University, Ashtian Branch and Dr. Mustafa Ghani

\section{Financial disclosure}

The authors declared no financial interest.

\section{Funding/Support}

This work was financially supported by the Ashtian Branch, Islamic Azad University, Iran.

\section{References}

1. Ozdemir MG, and Floros JD. Active food packaging technologies. Critical Reviews in Food Science and Nutrition 2004; 44 (3): 185-193.

2. Ahvenainen R. Novel Food Packaging Techniques. Woodhead Publishing Limited, Cambridge England 2003. P. 5-21.

3. Cha DS, Choi JH, Chinnan MS, and Park HJ. Antimicrobial films based on Na-alginate and kcarrageenan. Lebensm Wiss Technol 2002; 35(8): 715719.

4. De Baere H. Starch policy in the European community. Starch Biosynthesis Nutrition Biomedical 1999; 51(6): 189-193.

5. No HK, Meyers SP, Prinyawiwatkui W, and Xu Z. Applications of chitosan for improvement of quality and shelf life of foods: A Review. Journal of Food Science 2007; 72(5): 87-100.

6. Bourtoom TH, and Chinnan M. Preparation and properties of rice starch-chitosan blend biodegradable film. LWT-Food Science and Technology 2008; 41(3): 1633-1641.

7. Zhai M, Zhao L, Yoshii F, and Kume T. Study on antibacterial starch/chitosan blend film formed under the action of irradiation. Carbohydrate Polymer 2004; 57(1): 83-88. 
8. Wang W, Wu N, Zu YG, and Fu YJ. Antioxidative activity of Rosmarinus officinalis L. essential oil compared to its main components. Food Chemistry 2008; 108(3): 1019-1022.

9. Ding DM, Wang FJ, Liu XX, and Han CY. Antimicrobial effects of Cinnamon and Rosemary essential oils. Applied Mechanics and Materials 2015; 731: 385-388.

10. Bonilla J, Talon E, Atares M, Vargas A and Chiral T. Effect of the incorporation of antioxidant of physicochemical and antioxidant properties of wheat starch - chitosan films. Journal of food Engineering 2013;271-278.

11. Teodoro RAR, de Barros Fernandes RV, Borges S, and Souza A. Characterization of microencapsulated Rosemary essential oil and its antimicrobial effect on fresh dough. Food and Bioprocess Technology 2014; 7(9): 2560-2569.

12. Xu YX, Kim, KM, Hanna MA, and Nag D. ChitosanStarch composite film: Preparation and characterization. Industrial Crops and Products 2005; 21(2): 185-192.

13. Abdollahi M, Rezaei M, and Farzi G. A novel active bionanocomposite film incorporating rosemary essential oil and nanoclay into chitosan. Journal of Food Engineering 2012; 11: 343-350.

14. ASTM. Standard Test method for tensile properties of thin plastic sheeting. In Standards Designation D882. Annual Book of ASTM. Standards Philadelphia, American Society for Testing and Materials 2001: 162170.

15. ASTM (1995). Standard test methods for water vapor transmission of material E96-95. Annual book of ASTM. Philadelphia, Pa, American Society for Testing and Materials, 406-413.

16. Angles MN, and Dufrense A. Plasticized starchtunicin whikers nanocomposites.1. Structural Analysis. Macromolecules 2000; 33(22): 8344-8353.

17. Gontard N, Duchez CH, Cuq JL, and Guilbert S. Edible composite films of wheat gluten and lipids: water vapor permeability and other physical properties. Food Science and Technology 1994; 29(1): 39-50.

18. Institute of Standards and Industrial Research of Iran or ISIRI No. 997. General guidance for enumeration of yeasts and molds colony count technique at $25^{\circ} \mathrm{C} .1995$.

19. Institute of Standards and Industrial Research of Iran or ISIRI No. 6872. Food products-determination of aflatoxin B1 and total aflatoxins using HPLC and immunoaffinity column-Test method, 1 st revision. 2007.

20. Chillo S, Flores S, Mastromatteo M, Conte A, Gerschenson L, and Del Nobile MA. Influence of glycerol and chitosan on tapioca starch-based edible film properties. Journal of Food Engineering 2008; 88(2): 159-168.

21. Silva-weiss A, Bifani V, Ihl M, Sobral PJA, and Gomez-Guillen MC. Structural properties of films and rheology of film-forming solutions based on chitosan and chitosan-starch blend enriched with murta leaf extract. Food hydrocolloids 2013; 31: 458-466.

22. Shen XL, Wu JM, Chen Y, and Zhao G. Antimicrobial and physical properties of sweet potato starch films incorporated with potassium sorbate or chitosan. Food Hydrocolloids 2010; 24: 285-290.

23. Bongyekan CH, Aht-Ong D, and Srikulkit K. Preparation and properties evaluation of chitosancoated cassava starch films. Carbohydrate Polymers 2006; 63(1): 61-71.

24. Vasconez M, Flores SK, Campos CA, Alvarado J, Gerschensew N. Antimicrobial activity and physical properties of chitosan - tapioca starch based edible films and coatings. Food Research International 2009; 42: 762-769.

25. Talja RA, Helen H, Roos YH, and Jouppila K. Effect of various polyols and polyol contents on physical and mechanical properties of potato starch-based films. Carbohydrate Polymers 2007; 67(3): 288-295.

26. Pranto Y, Rakhshit SK, and Salokhe VM. Enhancing antimicrobial activity of chitosan films by incorporating garlic oil, potassium sorbate and nisin. LWT- Food Science and Technology 2005; 38(8): 859-865.

27. Rasooli I, Fakoor MH, Yadegarinia D, Gachkar L, Allameh A, and Rezaei MB. Antimycotoxigenic characteristics of Rosamarinus officinalis and Trachyspermum copticum L.essential oils. International Journal of Food Microbiology 2008; 122: 135-139.

28. Yan Q, Zhang J, Dong H, Hou H, and Guo P. Properties and antimicrobial activates of starch-sodium alginate composite films incorporated with sodium dehydroacetate or rosemary extract. Journal of Applied Polymer Science 2012; 127(3): 1951-1958.

29. Sikkma J, De Bont JAM, and Poolman B. Mechanisms of membrane toxicity of hydrocarbons. Microbiology and Molecular Biology Reviews 1995; 59: 201-222.

30. Deabes M, El-Soud N, and El-Kassem L. In vitro inhibition of growth and aflatoxin B1 production of Aspergillus flavus strain (ATCC 16872) by various medicinal plan essential oils. Macedonian Journal of Medicinal Sciences 2011; 4(4): 345 -350.

31. Moghtader M, Salari H, and Farahmand A. Evaluation of the antifungal effects of rosemary oil and comparison with synthetic borneol and fungicide on the growth of Aspergillus flavus. Journal of Ecology and the Natural Environment 2011; 3(6): 210-214.

32. Davidson PM, and Naiduand AS. Phyto-phenols. Natural Food Antimicrobial Systems 2000. CRC Press, Boca Raton, FL. p. 265-294.

33. Burt SA. Essential oils: their antibacterial properties and potential applications in foods- a review. International Journal of Food Microbiology 2004; 94(3): 223-253.

34. Namazi M, Allameh A, Aminshahidi M, Nohee A, and Malekzadeh F. Inhibitory effects of ammonia solution on growth and aflatoxins production by Aspergillus parasiticus. NRRL-2999. Acta Poloniae Toxicologica 2002; 10(1): 65-72. 